\title{
Factors influencing wolf Canis lupus roadkills in Northwest Spain
}

\author{
Victor Javier Colino-Rabanal • Miguel Lizana • \\ Salvador J. Peris
}

Received: 18 August 2009 /Revised: 31 July 2010 /Accepted: 13 August 2010 /Published online: 12 October 2010

(C) Springer-Verlag 2010

\begin{abstract}
Roadkill is one of the most prominent causes of wildlife mortality. Much research effort has focussed on collisions with ungulates because of traffic safety. However, studies about large carnivore roadkills are scarce despite vehicles being a main cause of mortality. The absence of studies can be explained in part because of difficulties in obtaining sufficient sample sizes. We collected data from locations of 82 wolf roadkill sites in the Castilla y León Region, northwest Spain. We evaluated different models to characterise collision localities using logistic regressions with corrections for rare events. The best models included traffic and human disturbance parameters. Landscape variables did not improve predictive power. Fencing was a decisive key predictor; roadkill was proportionally higher along fenced highways than on similar major roads that lacked fences. Wolf-vehicle collisions were more common in agricultural areas, although wolf densities were lower in these zones. Both the higher density of important roads and a greater proportion of roaming wolves on the plateau may explain this pattern.
\end{abstract}

Keywords Animal-vehicle collisions · Carnivores . Fencing $\cdot$ Logistic modelling $\cdot$ Roads $\cdot$ Wolf

Communicated by H. Kierdorf

V. J. Colino-Rabanal $(\bowtie) \cdot$ M. Lizana $\cdot$ S. J. Peris

Departamento de Biología Animal, Parasitología, Ecología,

Edafología y Química Agrícola, Área de Zoología,

Universidad de Salamanca,

Campus Miguel de Unamuno,

Salamanca 37007, Spain

e-mail: vcolino@usal.es

\section{Introduction}

Wildlife-vehicle collisions have increased in many parts of the world in recent decades with associated property damage, injury and fatalities (Conover et al. 1995). In Europe, accidents involving large mammals include wild boar Sus scrofa, roe deer Capreolus capreolus, red deer Cervus elaphus and elk Alces alces (Groot-Bruinderink and Hazebroek 1996). Although some populations may be at risk, road mortality is not a global threat to these species. The objective of mitigation is typically enhanced traffic safety rather than conservation. Important research efforts have focussed on identifying factors that explain the spatiotemporal distribution of roadkills, especially ungulates (Puglisi et al. 1974; Bashore et al. 1985; Finder et al. 1999; Hubbard et al. 2000; Joyce and Mahoney 2001; Nielsen et al. 2003; Malo et al. 2004; Mysterud 2004; Seiler 2004, 2005), but also large carnivores (Kolowski and Nielsen 2008) and smaller mammals (Inbar and Mayer 1999; Clevenger et al. 2003; Ramp et al. 2005; Bissonette and Rosa 2009; Grilo et al. 2009).

Nonetheless, roads can be one of the main mortality factors for large carnivores and have serious negative impacts on carnivore populations. Large carnivores have several characteristics that make them more vulnerable to road impacts: small population sizes, large home ranges with long daily movements and often behaviour that results in conflicts with human interests (Noss et al. 1996; Crooks 2002). For the Iberian lynx Lynx pardinus, roadkills accounted for $37.1 \%$ of the deaths (33 of 89) in the Parque Nacional de Doñana, Spain, between 1982 and 2004 (Ferreras et al. 1992; Ministerio de Medio Ambiente 2004). In Florida, half of cougar Felis concolor deaths are caused by vehicles (Harris and Gallagher 1989; Maehr 1991). 
The impact that roads have had on large carnivores is not limited to road mortality; habitat fragmentation and barrier effects may be the largest long-term threats to their population viability (McLellan and Shackleton 1988; Mace et al. 1996; Tigas et al. 2002; Kaczensky et al. 2003). Crossing structures are intended to improving connectivity by joining landscapes. The improvements made by underpasses and overpasses for use by large carnivores have been confirmed in several studies (Foster and Humphrey 1995; Rodríguez et al. 1996, 1997; Gloyne and Clevenger 2001; Grilo et al. 2008).

We investigated the possibility of modelling the spatial distribution of road-killed wolves Canis lupus that have large home ranges and long daily movements and use several kinds of habitat. Wolf-roads interactions have been studied previously. Wolves prefer landscapes without roads and avoid establishing territories in areas with a road density higher than $0.6 \mathrm{~km} / \mathrm{km}^{2}$ (Thiel 1985; Mech 1989; Mladenoff et al. 1995). Highways and major roads impede long-distance movements (Thurber et al. 1994; Paquet and Callaghan 1996), but transverse structures across linear infrastructures can reduce the barrier effect (Clevenger and Waltho 2000). Other authors have reported that highways are not a significant obstacle (Kohn et al. 1999) or, at least, fragmentation caused by a linear natural element, such as the River Duero, is greater than that caused by a four-lane highway (Blanco et al. 2005).

We are unaware of specific research about spatio-temporal distributions of wolf roadkill, although wolf mortality on roads is widely documented. There are several studies from the Mediterranean region documenting road mortality in wolves. In Italy, 52.0\% (76 roadkills) between 1991 and 2001 (Lovari et al. 2007) and in Croatia, 24.2\% (15 roadkills) between 1996 and 2001 (Huber et al. 2002) of the wolf mortality recorded were due to collisions with vehicles. Elsewhere, in Scandinavia, $26 \%$ of deaths $(n=84)$ were roadkill (Olsen 2003). In North America, on US Highway 53 in Wisconsin, one of 59 radio-tracked wolves and two non-telemetered wolves were killed on a road network during a 6-year study (Kohn et al. 1999). In Banff National Park, Canada, 16 wolf roadkills were recorded during an 18-year period (Clevenger et al. 2001).

The aim of this research is to describe which variables best characterise wolf-vehicle collisions in order to reduce the number of roadkills and improve mitigation planning decisions (Bissonette and Adair 2008). These parameters can be relative to traffic, landscape features or the degree of human presence.

\section{Materials and methods}

Study area and wolf populations

We conducted this study in the Castilla y León Region, which is situated in the Northwest Iberian Peninsula and including the
North Plateau and the peripheral mountainous area around it. Its total area is $94,223 \mathrm{~km}^{2}$, but wolf populations are not present in the whole region. Human population density is low, 26.57 inhabitants $/ \mathrm{km}^{2}$, and concentrated in towns and cities; there are also, however, many small villages throughout the region. There are two main landscapes within the study region. The plateau, now a grain-producing farmland landscape, is situated in the centre of the region, with a flat topography associated with the sediments of the River Duero and its tributaries. Surrounding the plateau, there is a range of mountains that can exceed $2000 \mathrm{~m}$ in height. Cattle grazing and forestry uses are the most common land-uses in the peripheral mountains (Fig. 1). Castilla y León road type characteristics are described in Table 1.

Wolf populations have increased in both Europe and North America, re-colonising agricultural regions where they were formerly extirpated (Mech 1995; Boitani 2003). Wolves now occupy the northwestern quadrant of the Iberian Peninsula and have a current population estimated at 2,000 individuals (Blanco et al. 2007). In the Castilla y León Region, the most recent census is 149 packs (107 confirmed and 42 probable). Wolves occupy a part of $75,200 \mathrm{~km}^{2}$, mainly to the north of the River Duero, although some have managed to cross the river and some packs are established to the south of this river. Populations have experienced a continuous expansion that indicates saturation of areas previously occupied and recolonisation of former parts of their distribution that are now transformed into agricultural lands. Both spatial distribution and population size have increased slowly, but continuously. Maximum densities are found in the northwest (32 packs estimated in $8,000 \mathrm{~km}^{2}$ ) and the north (30 packs in $7,000 \mathrm{~km}^{2}$ ). The lowest density is located to the south of the River Duero, with only around 15 packs in $19,700 \mathrm{~km}^{2}$ (Llaneza and Blanco 2005).

\section{Data collection}

We collected a total number of 82 reports about road-killed wolves in the period 2001-2007. The data were derived from reports submitted by traffic safety authorities. We have also collected data from the Section of Natural Spaces and Protected Species of the Junta de Castilla y León (Regional Government). These data include information about the road and the kilometre point where the collision took place and the date and time of the event. Only 77 of the 82 collision sites were well defined. In $9.09 \%$ of the data, the level of accuracy had an error of $500 \mathrm{~m}$, and in the other $90.90 \%$, the level of accuracy was $50 \mathrm{~m}$ (if the hectometre was included in the record). This level of accuracy avoids the problem cited by Gunson et al. (2009). Nonetheless, higher errors could be introduced by the collision localities in fenced highways because, once they have managed to enter the fenced highway zone, wolves could move and be road-killed on 


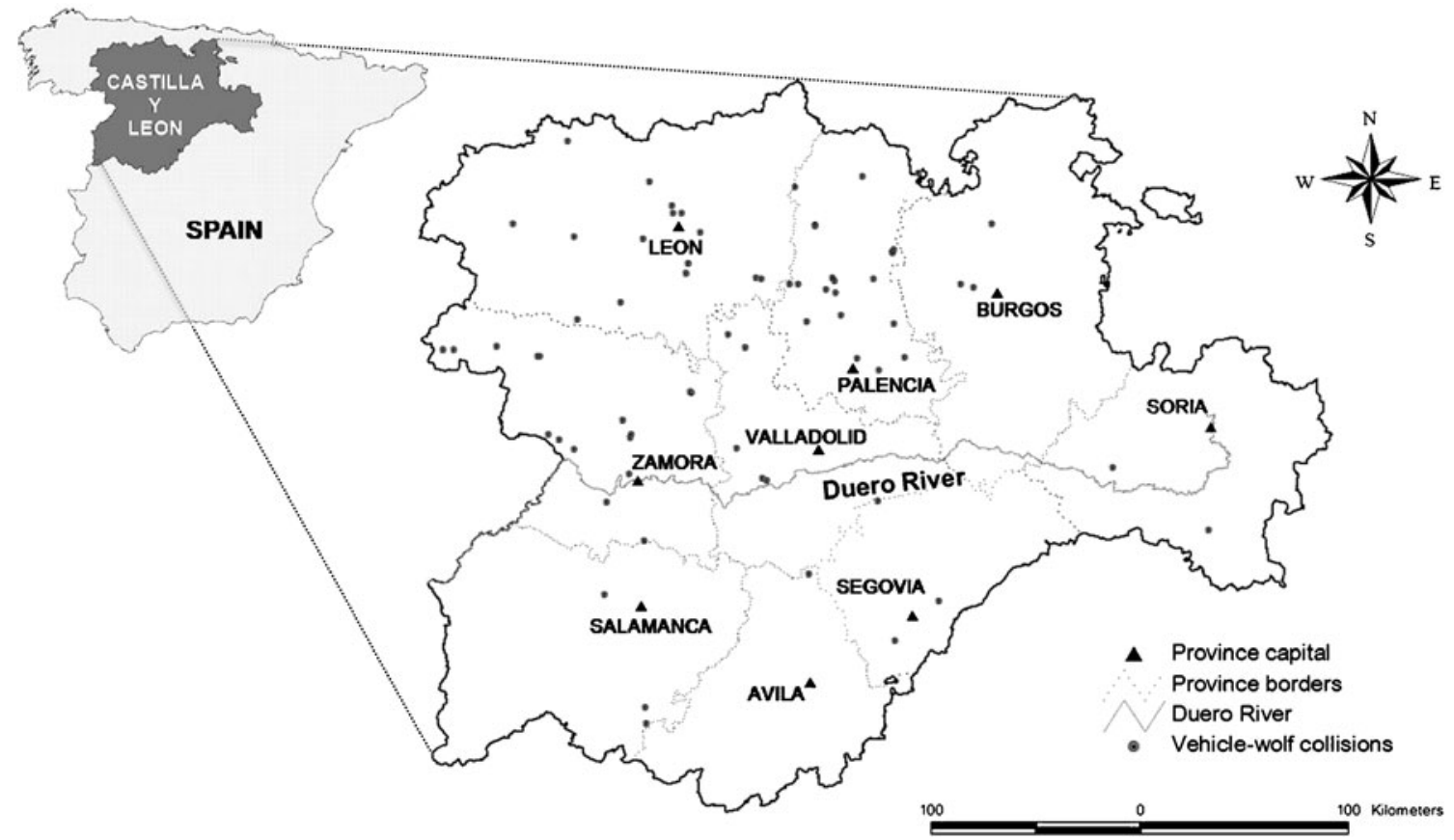

Fig. 1 Location of the study area. White points indicate wolf roadkill localities in the Castilla y León road network from 2001 to 2007. Data were obtained from reports by traffic safety and environmental authorities

the road far away from the access point. The number of roadkilled wolves is likely to be higher (Slater 2002). We have not been able to estimate the unreported collision percentage, but it could be significant. The wolf is an emblematic species, and it is probable that some drivers involved in a vehiclewolf collision, frightened of being fined, may decide not to report the collision to traffic safety authorities.

Table 2 shows the 17 variables included in wolf-vehicle collision modelling. Traffic volume and velocity were extracted from the 2005 Map of Traffic Volume and Speed recorded by the Department of Development of the Junta de Castilla y León or by the Ministry of Development depending on the authority responsible. Sinuosity was calculated from digital road maps using a $2-\mathrm{km}$ segment with the roadkill location as the centre of the segment.

Land uses were obtained from the National Forestry Map made from aerial photography by the Spanish Ministry of the Environment at a scale of 1:50,000. This land-use classification defines 33 land uses. We have only taken into account those which have greater ecological and quantitative importance (Table 2). Other geographical elements were extracted from topographic digital maps at a scale of 1:50,000. Slope was derived from a digital elevation model (resolution of $25 \mathrm{~m}$ ) produced by the Spanish National
Table 1 Main characteristics of the different types of roads within Castilla y León road network

\begin{tabular}{|c|c|c|c|c|}
\hline $\begin{array}{l}\text { Type of } \\
\text { road }\end{array}$ & Function & $\begin{array}{l}\text { Number } \\
\text { of lanes }\end{array}$ & $\begin{array}{l}\text { Traffic } \\
\text { volume } \\
\text { and speed }\end{array}$ & Fencing \\
\hline Motorways & $\begin{array}{l}\text { Connect the main } \\
\text { cities throughout } \\
\text { the country }\end{array}$ & $\begin{array}{l}4 \text { or } \\
\text { more }\end{array}$ & High & $\begin{array}{l}\text { Always fenced; conventional road fences } \\
\text { of } 1.8 \mathrm{~m} \text { in height, made of galvanised } \\
\text { steel with a mesh size of } 10-15 \mathrm{~cm} \text { and } \\
\text { a distance of about } 4 \mathrm{~m} \text { between posts }\end{array}$ \\
\hline $\begin{array}{l}\text { National } \\
\text { roads }\end{array}$ & $\begin{array}{l}\text { Connect important } \\
\text { populated areas at a } \\
\text { national scale }\end{array}$ & 2 & $\begin{array}{l}\text { High- } \\
\text { medium }\end{array}$ & Rarely fenced \\
\hline $\begin{array}{l}\text { Regional } \\
\text { roads }\end{array}$ & $\begin{array}{l}\text { Connect important } \\
\text { populated areas at a } \\
\text { regional scale }\end{array}$ & 2 & Medium & Rarely fenced \\
\hline $\begin{array}{l}\text { Secondary } \\
\text { roads }\end{array}$ & $\begin{array}{l}\text { Connect villages and } \\
\text { other less } \\
\text { frequented places }\end{array}$ & 2 & Low & Rarely fenced \\
\hline
\end{tabular}


Table 2 Traffic, landscape and human presence variables measured for both roadkill localities and random distributed control sites

Variables were grouped in three types of models: traffic parameters' model (TM), landscape parameters' models (LM) and anthropogenic influence parameters model (AM). Landscape variables were considered on three spatial scales using buffers of $1,000,2,500$ and $5,000 \mathrm{~m}$

\begin{tabular}{llll}
\hline & Variables & Units & Type \\
\hline TM & Traffic density (density) & Hundreds of vehicles per day & Continuous \\
& Traffic speed (speed) & Kilometres per hour & Continuous \\
& Road length/linear distance (sinuosity) & Dimensionless & Continuous \\
& 1.8-m height fences along roads (fences) & Presence/absence & Discrete \\
LM & Slope & $\%$ & Continuous \\
& Proportion of forest (forest) & $\%$ & Continuous \\
& Proportion of reforested area (reforest) & $\%$ & Continuous \\
& Proportion of shrubs (shrubs) & $\%$ & Continuous \\
& Proportion of unirrigated crops (unirrigat) & $\%$ & Continuous \\
& Proportion of irrigated crops (irrigated) & $\%$ & Continuous \\
& Distance to river or stream (water) & Hundreds of metres & Continuous \\
& Shannon landscape diversity index (SDI) & Dimensionless & Continuous \\
& Ecotone density (ED) & Dimensionless & Continuous \\
AM & Distance to populated area (popularea) & Hundreds of metres & Continuous \\
& Distance to municipal border (municbord) & Hundreds of metres & Continuous \\
& Distance to railway (railway) & Hundreds of metres & Discrete \\
& Distance to canal (canal) & Hundreds of metres & Discrete \\
\hline
\end{tabular}

Geographic Institute from contour lines and elevation points contained in the National Topographic Map at a scale of 1:25,000. Software used in geographical information system analyses was ArcGis 9.0. (ESRI Corp).

Statistical analysis

\section{Logistic regression for rare events}

We modelled the characteristics of wolf roadkill sites using a logistic regression. This kind of regression describes the relationship between a dichotomous variable $(Y)$ and a group of independent variables $\left(x_{1}, x_{2}, \ldots, x_{n}\right)$. Explanatory variables can be continuous or discrete and do not have to follow normal distribution. The function can be written as

$P(Y=1)=\widehat{p}=\frac{1}{1+e^{-\left(\alpha+\beta_{1} x_{1}+\beta_{2} x_{2}+\ldots+\beta_{n} x_{n}\right)}}$

We compared the observed distribution to a random distribution. Because the sample sizes of large carnivore roadkills in studies, such as ours, are often small, the random point distribution will be low too, and we could introduce a bias in spite of random assumption. A solution could be to compare roadkill distribution with a larger number of generated random points. Thus, we can treat wolf roadkills as a rare event in a finite sample. For rare events, the positive event number is much lower than negative events. However, logistic regression robustness requires that positive/negative observations are not unbalanced. Unbalanced data can introduce severe bias in probability prediction (Cramer 1999; King and Zeng 2001). King and Zeng (2001) have developed a method for these cases that incorporates three corrections for logistic regression.

Firstly, we do not compare wolf roadkill distribution with a matched number of random points, but rather we selected a 0 -s sample five times more numerous, which is more representative and less influenced by randomness.

If sample generation responds to a case-control design, a second correction is required. This so-called prior correction is intended to avoid bias in logistic coefficients because of dependent variable selection (King and Zeng 2000, 2001). Intercept $\beta_{0}$ is corrected using the following equation:

$\beta_{0}=\widehat{\beta}_{0}-\ln \left[\left(\frac{1-\tau}{\tau}\right)\left(\frac{\bar{y}}{1-\bar{y}}\right)\right]$

where $\tau$ is the actual fraction of $1 \mathrm{~s}$ in the population, and $y$ the observed fraction of $1 \mathrm{~s}$ in the sample data.

However, we can underestimate the probability when we substitute the corrected coefficient in Eq. 1 because of uncertainty in the estimation of $\hat{\beta}$. For this reason, a third correction is required, incorporating the sum of a factor $C_{i}$ to $\widetilde{p}_{i}$. Corrected probabilities are

$P\left(Y_{i}=1\right)=\widetilde{p}_{i}+C_{i}$

Factor $C_{i}$ for each element can be obtained using the equation:

$C_{i}=\left(0.5-\widetilde{p}_{i}\right) \widetilde{p}_{i}(1-\widetilde{p}) X V(\beta) X^{\prime}$

where $V(\beta)$ is the variance-covariance matrix, $X$ is a $1 \times(n+$ 1) vector of values for each independent variable and $X^{\prime}$ is the transposed matrix of $X$. 
Initially, in order to identify which of the selected putative predictor variables differed between roadkill and random point distributions, we developed a univariate means comparison using an unpaired sample $t$ test. Univariate logistic regressions were used for categorical variables. Variables with significant differences between both distributions $(\alpha>0.1)$ were included in later models. We generated stepwise logistic models with rare event corrections using the zelig analysis package available in the statistical software $R$ (Imai et al. 2007, 2008). Before this analysis, we calculated bivariate correlations to detect undesired multi-co-linearity effects. We removed one of the variables when the correlation was higher than 0.7 , selecting the variable with a lower $t$ statistic in the univariate test for elimination.

We generated several models with the different variable types that could explain the spatial distribution of wolfvehicle collisions (Table 3): traffic and road characteristics (traffic model (TM)), surrounding landscape (landscape model (LM)) or degree of disturbance by human elements (anthropogenic model (AM)). Each model was first tested separately, and later, all possible combinations between them were tried. We analysed the landscape model using three spatial scales (radii of 1,000, 2,500 and 5,000 m around a point) to identify the optimum spatial scale for analysis. Significance level to enter models was 0.05 .

The most parsimonious model was obtained using the Akaike information criterion (AIC; Akaike 1973), which is a good method to select which variables should be included or excluded in models. This criterion considers both fit and complexity and allows simultaneous comparison among several models (Burnham and Anderson 2002). The predictive value of the models was evaluated using a receiver operating characteristic (ROC) curve. Area under the ROC curve (AUC) varies from 0.5 to 1 , where higher values indicate better predictive utility of the model (Fielding and Bell 1997; Pearce and Ferrier 2000). Predictive models require a validation of results; with this objective, the sample was divided into two groups: $80 \%$ of the data was used in model creation, and the other $20 \%$ was used in model validation. We have validated our models applying them to a sample of 95 data points not used previously in the calibration stage.

\section{Other statistical analysis}

As the fence was only located on motorways, we found necessary to draw out the confounding effects of traffic volume and fence presence. With this purpose, the number of wolf roadkill per kilometre grouped by road type was analyzed with a repeated-measures analysis of covariance (ANCOVA). A repeated-measures time factor (year) and a between-subjects road fence presence factor were included in the analysis. Since the number of wolf roadkills per kilometre may be affected by traffic volume, this variable was included as a covariate. The Greenhouse-Geisser degrees of freedom adjustment procedure was applied to the repeated-measures time factor to correct for violations of sphericity that often occur with repeated-measures analyses. Moreover, to investigate temporal variations in wolf roadkills, annual and daily wolf-vehicle collision patterns were analysed using the Kruskal-Wallis test.

\section{Results}

\section{Univariate tests}

We found significant differences between roadkill localities and the random sites, especially in traffic parameters, but also with variables related to the degree of human presence. Landscape parameter differences were less clear (Table 4). Observed collision sites vary from random points because they tended to be located on fenced roads, with low sinuosity, higher traffic intensity and higher speeds, further away from anthropogenic elements and closer to adminis-
Table 3 Models tested to identify the predictors of roadkill sites

We generated five simple models. Each model contains traffic variables, surrounding landscape elements or variables indicating the degree of human presence. We evaluated landscape models on three spatial scales with buffers of 1,000, 2,500 and $5,000 \mathrm{~m}$ around the collision site. In addition, we evaluated some models that include multiple thematic variables

\begin{tabular}{|c|c|c|}
\hline \multirow{2}{*}{$\overline{\text { Model }}$} & & \multirow[t]{2}{*}{ Abbreviation } \\
\hline & & \\
\hline \multicolumn{2}{|c|}{ Traffic parameters' model } & $\mathrm{TM}$ \\
\hline \multicolumn{2}{|c|}{ Landscape parameters' model (radius $1,000 \mathrm{~m}$ ) } & LM1000 \\
\hline \multicolumn{2}{|c|}{ Landscape parameters' model (radius 2,500 m) } & LM2500 \\
\hline \multicolumn{2}{|c|}{ Landscape parameters' model (radius $5,000 \mathrm{~m}$ ) } & LM5000 \\
\hline \multicolumn{2}{|c|}{ Anthropogenic influence parameters' model } & $\mathrm{AM}$ \\
\hline \multicolumn{3}{|l|}{ Combined models } \\
\hline TM+LM1000 & $\mathrm{TM}+\mathrm{LM} 1000$ & $\mathrm{TM}+\mathrm{LM} 1000+\mathrm{AM}$ \\
\hline TM+LM2500 & $\mathrm{TM}+\mathrm{LM} 2500$ & $\mathrm{TM}+\mathrm{LM} 2500+\mathrm{AM}$ \\
\hline TM+LM5000 & $\mathrm{TM}+\mathrm{LM} 5000$ & $\mathrm{TM}+\mathrm{LM} 5000+\mathrm{AM}$ \\
\hline $\mathrm{TM}+\mathrm{AM}$ & & \\
\hline
\end{tabular}


Table 4 Results of univariate comparisons of variables shown in Table 1 comparing 62 roadkill localities with 320 random sites in the road network

\begin{tabular}{|c|c|c|c|c|}
\hline & $t$ value & $d f$ & $p$ & $\gamma^{2}$ \\
\hline Density & 5.062 & 75 & $<0.001$ & \\
\hline Speed & 9.672 & 380 & $<0.001$ & \\
\hline Sinuosity & -5.130 & 210 & $<0.001$ & \\
\hline Slope & -0.768 & 380 & 0.443 & \\
\hline Forest1000 & -0.382 & 380 & 0.703 & \\
\hline Reforest1000 & -0.397 & 380 & 0.692 & \\
\hline Shrub1000 & -0.644 & 380 & 0.520 & \\
\hline Unirrigat 1000 & 2.055 & 380 & 0.041 & \\
\hline Irrigated 1000 & 1.650 & 74 & 0.093 & \\
\hline SDI1000 & -1.514 & 380 & 0.131 & \\
\hline ED1000 & -1.714 & 380 & 0.087 & \\
\hline Forest 2500 & -0.376 & 380 & 0.707 & \\
\hline Reforest 2500 & 0.003 & 380 & 0.998 & \\
\hline Shrub2500 & -0.600 & 380 & 0.549 & \\
\hline Unirrigat2500 & 1.458 & 93 & 0.148 & \\
\hline Irrigated 2500 & 1.634 & 72 & 0.107 & \\
\hline SDI2500 & -0.142 & 380 & 0.887 & \\
\hline ED2500 & 0.119 & 380 & 0.906 & \\
\hline Forest5000 & -1.746 & 99 & 0.084 & \\
\hline Reforest5000 & 0.350 & 380 & 0.726 & \\
\hline Shrub5000 & -0.743 & 380 & 0.458 & \\
\hline Unirrigated5000 & 2.021 & 380 & 0.044 & \\
\hline Irrigated5000 & 1.984 & 74 & 0.051 & \\
\hline SDI5000 & -0.542 & 380 & 0.588 & \\
\hline ED5000 & -1.770 & 380 & 0.078 & \\
\hline Municbord & -2.976 & 99 & 0.004 & \\
\hline Water & 1.508 & 380 & 0.132 & \\
\hline Popularea & 2.222 & 119 & 0.028 & \\
\hline Fences & & 1 & $<0.001$ & 32.013 \\
\hline Railway & & 1 & 0.404 & 0.697 \\
\hline Canal & & 1 & 0.516 & 0.422 \\
\hline
\end{tabular}

trative borders. With the landscape variables, we found significant differences only for those obtained with radii of 1,000 and $5,000 \mathrm{~m}$. There were no differences between roadkill points and random sites for a radius of $2,500 \mathrm{~m}$. At both scale extents, 1,000 and 5,000, wolf roadkill localities were more common in homogeneous landscapes with low ecotone density and both non-irrigated and irrigated crop predominance.

Logistic regression with rare event correction

Table 5 presents the results for logistic regression models with the rare event correction included. We only developed four of the five simple models considered at the beginning, because no significant differences were found for variables included in the landscape parameters' model with a radius of 2,500 m (LM2500). The Wald Chi test only found significant variables for the traffic parameters' model (TM) and the anthropogenic influence parameters' model (AM). For the landscape parameters' model with a radius of $1,000 \mathrm{~m}$ (LM1000) and the landscape parameters' model with a radius of 5,000 $\mathrm{m}$ (LM5000), no variable had a significance level below 0.05 . TM includes speed, sinuosity and fence presence. AM only includes distance to municipal limits.

Table 5 shows the comparison among models by means of AIC. Between all simple models, TM had the lowest AIC value (289.2). For the other three simple models, the results are slightly higher. A small decrease in AIC values among regression models without significant variables indicates a limited predictive capacity for all models. $\mathrm{TM}+\mathrm{AM}$ has an AIC value of 284.3, which means that TM improved by the addition of AM variables. However, the small decrease indicates that AM contribution to model predictive power is not very substantial.

The area under the ROC curve (AUC) for calibration data differs among models (Table 5), being moderate for those that include traffic parameters and low for the others (lower than 0.634 ). TM+AM+LM5000 works slightly better (0.847) than TM+AM (0.843) and TM (0.841). These small differences can also be observed in the ROC curve shown in Fig. 2. Nevertheless, TM+AM+LM5000 shows a higher AIC value than the TM+AM. Therefore, we considered that the $\mathrm{TM}+\mathrm{AM}$ was the model that worked best. In addition to traffic parameters, the degree of human disturbance also is important for the identification of potential wolf-vehicle collision points in our study region. This model includes speed, road fence presence and distance to anthropogenic elements as predictive variables, all of them positively correlated with collision occurrence. Odds ratio results $(\mathrm{e} \beta)$ show a $40 \%$ increase in roadkill probability for each $10-\mathrm{km}$ increase in speed. It increases by $3.2 \%$ for each $100-\mathrm{m}$ distance from an anthropogenic element. It is especially remarkable that the presence of road fences increases roadkill probabilities by 3.19 times (Table 5). AUC for the validation dataset (Fig. 2 and Table 6) is higher than the one obtained for calibration data. This is an unexpected result and perhaps consequence of the small sample size.

Type of road, the effect of fencing and roadkill concentration in time

The importance of road fences and traffic parameters can be verified by the index of the number of wolf mortalities per kilometre of road per year. This index is much higher for motorways $(2.96 \pm 1.57$ annual collisions $/ 1,000 \mathrm{~km}, 30.0 \%$ of the total) and is significantly different from other roads 
Table 5 Results of logistic regression models including rare event corrections generated to identify the spatial distribution in wolf-vehicle collisions

The models have been calibrated using observed and random points

\begin{tabular}{llccrrr}
\hline & & Coefficient $(B)$ & Std. error & Wald & $p(>|\mathrm{z}|)$ & Odds ratio \\
\hline TM & Intercept $\alpha$ & -9.98 & 1.09 & -9.19 & $<0.001$ & \\
& Speed & 0.04 & 0.01 & 3.56 & $<0.001$ & 1.043 \\
& Sinuosity & -0.02 & 0.03 & -0.79 & 0.427 & 0.980 \\
\multirow{2}{*}{ LM1000 } & Fences & 1.01 & 0.50 & 2.02 & 0.044 & 2.743 \\
& Intercept $\alpha$ & -5.276 & 0.597 & -8.83 & $<0.001$ & \\
& Unirrigated1000 & 0.004 & 0.005 & 0.94 & 0.350 & 1.004 \\
& Irrigated1000 & 0.009 & 0.006 & 1.47 & 0.140 & 1.009 \\
& ED1000 & -0.004 & 0.006 & -0.77 & 0.440 & 0.996 \\
& Intercept $\alpha$ & -5.246 & 0.855 & -6.13 & $<0.001$ & \\
& Forest5000 & -0.003 & 0.011 & -0.23 & 0.822 & 0.997 \\
& Unirrigated5000 & 0.003 & 0.008 & 0.39 & 0.699 & 1.003 \\
& Irrigated5000 & 0.017 & 0.009 & 1.82 & 0.068 & 1.017 \\
& ED5000 & -0.005 & 0.011 & -0.5 & 0.614 & 0.995 \\
& Intercept $\alpha$ & -1.963 & 0.282 & -6.97 & $<0.001$ & \\
& Municbordi & -0.042 & 0.018 & -2.31 & 0.021 & 0.958 \\
& Popularea & 0.018 & 0.012 & 1.44 & 0.151 & 1.018 \\
& Intercept $\alpha$ & -5.764 & 1.177 & -4.9 & $<0.001$ & \\
& Speed & 0.039 & 0.012 & 3.26 & 0.001 & 1.040 \\
& Sinuosity & -0.022 & 0.026 & -0.86 & 0.392 & 0.978 \\
& Fences & 1.160 & 0.511 & 2.27 & 0.023 & 3.191 \\
& Municbord & -0.034 & 0.020 & -1.7 & 0.089 & 0.967 \\
& Popularea & 0.031 & 0.014 & 2.18 & 0.029 & 1.032 \\
\hline
\end{tabular}

$\left(\gamma^{2}=23.020, d f=3, p<0.001\right)$. National roads have a lower index but still high $(0.80 \pm 0.28$ roadkills per year $/ 1,000 \mathrm{~km}$, $33.8 \%)$. For the regional road network $(0.21 \pm 0.17$ roadkills per year $/ 1,000 \mathrm{~km}, 18.8 \%)$ and secondary roads $(0.11 \pm$ 0.05 roadkills per year $1,000 \mathrm{~km}, 17.5 \%$ ), wolf-vehicle collisions are infrequent relative to total network length. The repeated-measures ANCOVA of the number of wolf roadkills per kilometre (controlled for traffic volume) demonstrated a significant main effect for fence presence $\left(F_{1,1}=292.521, p=0.037\right)$. No effect for time was found in the repeated-measures analysis.

We found no significant annual pattern $\left(\gamma^{2}=17.794, d f=\right.$ $11, p=0.086$ ), but roadkill frequencies were higher from November to April, which coincided with the breeding
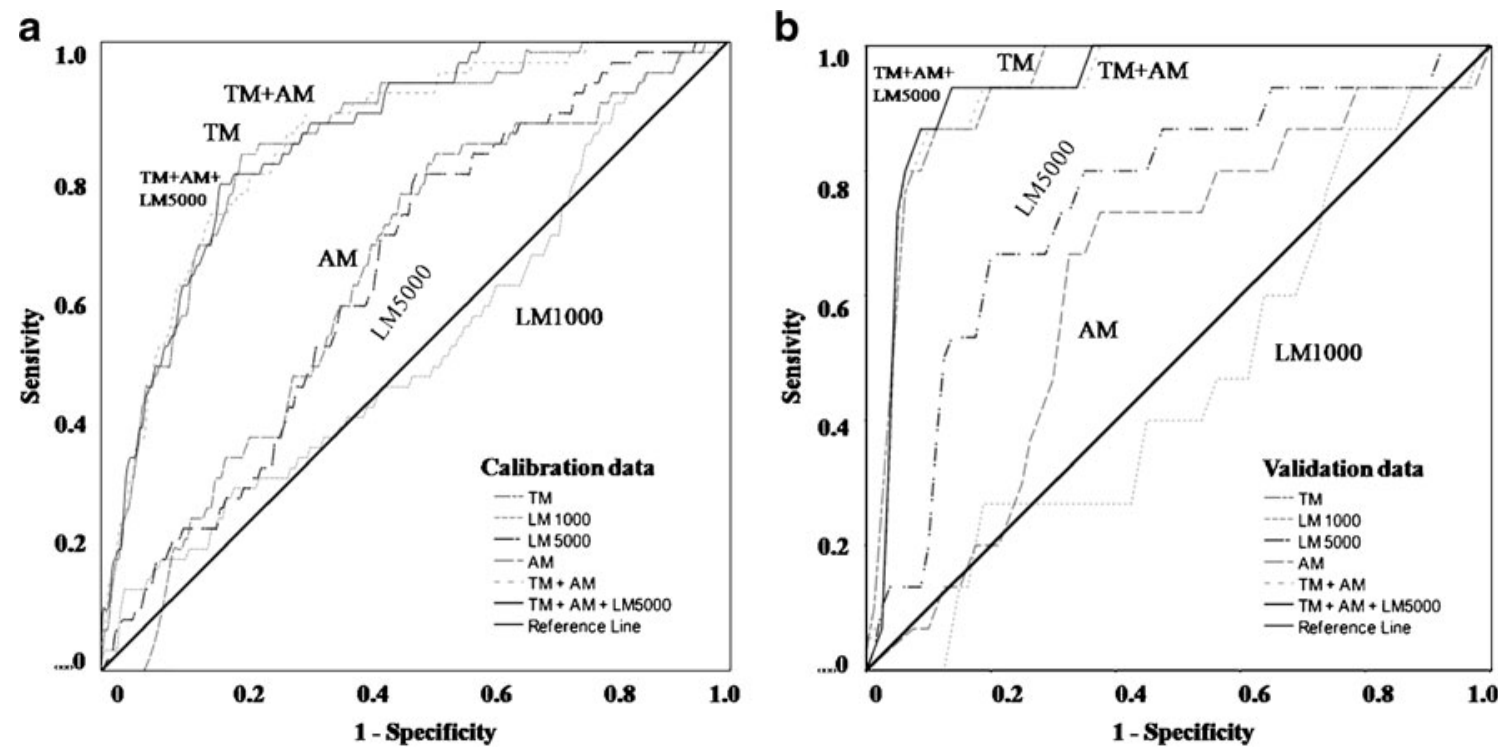

Fig. 2 Receiver operating characteristic (ROC) curves obtained for each model with both a calibration and b validation data 
Table 6 Comparison among models using the Akaike information criterion and area under the ROC curve (AUC) for both calibration and validation data

\begin{tabular}{lccc}
\hline & AIC & AUC calibration & AUC validation \\
\hline TM & 289.2 & 0.841 & 0.935 \\
LM1000 & 341.4 & 0.518 & 0.463 \\
LM5000 & 340.0 & 0.631 & 0.752 \\
AM & 335.3 & 0.634 & 0.626 \\
TM+AM & 284.3 & 0.843 & 0.928 \\
TM+AM+LM5000 & 288.7 & 0.847 & 0.933 \\
\hline
\end{tabular}

season and hunting period (Fig. 2). Nevertheless, the daily pattern is significant $\left(\gamma^{2}=66.299, d f=23, p<0.001\right)$. Peaks occur during maximum activity periods that coincide with high traffic intensity. The result is a bimodal curve with two peaks: one at dusk and the first hours of the night and the other at sunrise (Fig. 3).

\section{Discussion}

The best predictive model for wolf roadkills includes not only traffic parameters but also the degree of human
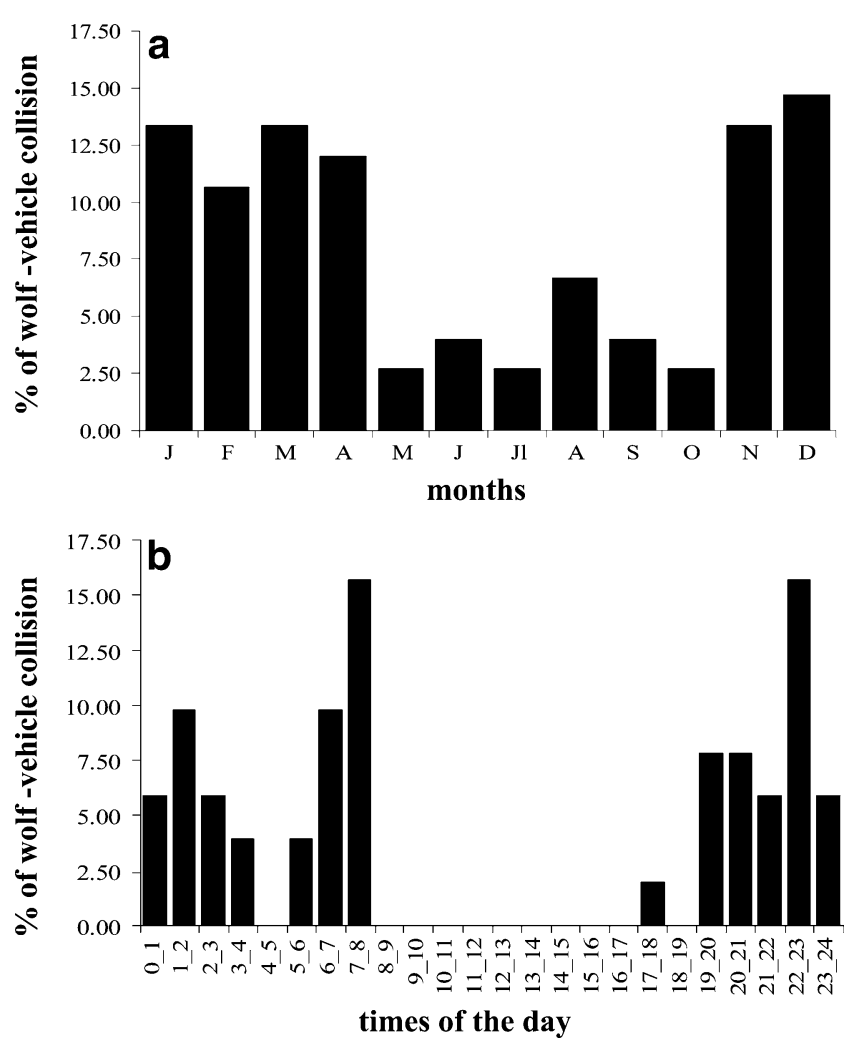

Fig. 3 Temporal distribution of wolf-vehicle collisions: a months and b times of the day presence. Landscape variables hardly improve models. The results are different from those reported in models for large ungulate collisions where landscape variables play important roles (Puglisi et al. 1974; Bashore et al. 1985; Finder et al. 1999). Forest proximity and traffic parameters are the main explanatory variables in elk collisions (Seiler 2005). These variables were similar to those found in Soria Province, included in our study region, where hotspots of ungulate-vehicle collisions are located in forested areas with quite low agricultural cover, certain landscape diversity and low human presence (Malo et al. 2004). Moreover, wolves are large carnivores that can adapt to different kinds of habitat, with extensive home ranges and long daily movements in which they move through a mosaic of patch types. Thus, predictive modelling with coarse, general landscape variables used in this study did not add to the model. Neither land uses nor landscape structure indices, regardless of the analysis of scale, have been useful in logistic models. Nonetheless, it could be possible to find differences with a larger sample size.

Collisions with wolves tend to occur along roads where high speeds and traffic intensity exist, as has been reported for accidents involving ungulates (Seiler 2005). It is noteworthy that fences along roads play an important role in wolf roadkills. Many of them occur on fenced roads, mainly motorways. The number of collisions per kilometre and year on unfenced major roads is proportionally lower, although they have dense traffic at high speeds. Repeatedmeasured ANCOVA results showed that it not a confounding effect of traffic volume. The effectiveness of Spanish motorway fences is insufficient for the well-being of the wolf populations. Moreover, the absence of animal-escape mechanisms in the older motorways for wolves to escape the right-of-way away from the road aggravates the situation. Another possible interpretation of the results is that the lower roadkill rates in unfenced roads with heavy traffic volumes could be related to wolf behaviour. Wolves may select positively the right moment to cross the road and avoid the collision. Future research should focus on wolf behaviour when a vehicle is coming down the road. The results about the fence effectiveness are different from other studies which showed that road fences contribute to a decrease in road mortality but also increase barrier effect (Jaeger and Fahrig 2004). Ward (1982), Lavsund and Sandegren (1991) and Clevenger et al. (2001) found that fencing and wildlife crossing structures can reduce ungulate collisions by $80 \%$. Moose collisions are more frequent on unfenced medium-traffic roads (Seiler 2005). Fences act as selective filters but do not have the same effectiveness for all species. Some carnivore species can occasionally overcome road fences due to their strength or jumping and climbing abilities. When wildlife gains access to a motorway, fences have the opposite effect to that desired, 
increasing the time the animal stays on the road and the probabilities of being killed. We are not saying that fences are not useful but that construction failures and lack of maintenance favour wildlife access to the road and diminish fence effectiveness. Clevenger et al. (2001) reported that only two of the six deaths of wolves took place after fencing, but the sample size was so small that no conclusions could be drawn. Black bears Ursus americanus, grizzly bears Ursus arctos and cougars Puma concolor were capable of climbing fences. Coyotes Canis latrans reached the road through holes between the fences and ground. The Iberian lynx can easily penetrate fences with a large mesh size, not fixed to the ground and without overhangs (Guzmán et al. 2004). It is necessary to investigate the efficacy of different types of fences for carnivores. Furthermore, it is necessary to focus on escape mechanisms that allow carnivores inside fenced roads to reach the exterior again. Several designs have been proposed, e.g. lateral doors of escape or ramps built with different materials and designs (Iuell et al. 2003).

Researchers have also included in roadkill modelling some indicators of the degree of anthropogenic disturbance. Like other species (Bashore et al. 1985;Clevenger et al. 2003), wolves positively select undisturbed areas. In this way, municipal limit closeness and human settlement remoteness are good indicators. Administrative borders are historically tranquil areas with low human presence. Clevenger and Waltho (2000) found that carnivores selected road-crossings far from anthropogenic elements and with low human disturbance. Rodríguez et al. (1997) verified the same behaviour for red foxes Vulpes vulpes and wild cats Felis silvestris. Wolves accustomed to human presence may frequent the vicinity of small villages. Blanco et al. (2005) indicated that radio-marked wolves used road-crossing structures placed closer than $200 \mathrm{~m}$ to inhabited houses. It is probable that wolves accustomed to human presence would be less reluctant to cross motorways than populations established in remote areas (Blanco et al. 2005).

Although they did not contribute to improve model fit, landscape variables in roadkill localities differed slightly from random sites. Wolf-vehicle collisions tended to be located in agricultural areas. On the agricultural plateau, wolf density $\left(2.4-3.0\right.$ wolves $\left./ 100 \mathrm{~km}^{2}\right)$ is not as high as in other undisturbed forest areas of the mountainous periphery (maximum density in the northwest Zamora Province with $6.0-7.2$ wolves $/ 100 \mathrm{~km}^{2}$; Blanco and Cortés 2002). Carrion abundance can be the main factor to explain the permanent presence of wolves in an atypical area, such as the plains with their cereal crops. Because of carrion, wolves do not have to attack livestock as often which is why do not come into conflict with humans and persecution is less intense (Barrientos 2000). The higher number of wolf-vehicle collisions on the plateau could be explained not only by higher densities of roads with intense traffic but also by the proportion of roaming individuals. Wolf movement characteristics may be even more important than population density. It is probable that a low quality habitat and a large quantity of food provided by dumps favour a high percentage of non-territorial individuals (Blanco and Cortés 2002). This has been shown in coyotes (Todd and Keith 1976). Roaming individuals undergo higher rates of mortality because they wander around areas influenced by humans (Blanco and Cortés 2002). Wolves, radio-marked by Blanco and Cortés (1999), on the steppes cultivated with cereal crops spent $40.8 \%$ of the time as peripheral and roaming individuals. Dispersed wolves suffer a higher proportion of deaths (Fuller 1989; Waser 1996; Pletscher et al. 1997). Blanco and Cortés (2002) measured the annual rate of dispersion on the plateau at $48.6 \%$. Several roadkills have taken place in areas where the species is not well established, which may coincide with the young dispersing or roaming individuals. Although we could not obtain data about the ages and sexes of road-killed wolves, according to Lovari et al. (2007), it is more probable that the young suffer the highest roadkill frequencies.

In conclusion, it is difficult to obtain good models for the roadkills of large carnivore species such as wolves because of their small population sizes, large home ranges and long daily movements. They use different habitats, so landscape variables are not very useful for the prediction of collision locations. These results suggest that it is difficult to focus permanent mitigation structure locations, e.g. underpasses or overpasses within the road network. Perhaps with a bigger sample size, it would be possible to find patterns, but wolf-vehicle collisions can be considered as rare events, so larger samples are difficult to encounter for suitable spatio-temporal scales. Only variables relative to traffic and road parameters and the degree of anthropogenic disturbance can partially explain spatial distribution. Therefore, the importance of road fences should be taken into account. Future research should focus on the specific specs of fences and animal-escape mechanisms to be effective. Roadkill minimisation also requires the correct installation and maintenance of the fences. Wolf roadkills in the region of study are proportionally more common in agricultural zones, where wolf densities are lower. This fact might be explained by the higher density of roads with intense traffic and the longer daily movements of the animals. Furthermore, the ecological characteristics of this area imply a high percentage of roaming individuals, which are more frequently killed on the roads. If roaming individuals were the principal victims of roadkills, the consequences for population viability might be lower. 
Acknowledgements Traffic reports used in this study were contributed by the Traffic Safety Observatory of the Dirección General de Tráfico, the Traffic Subsectors of the Guardia Civil and the Servicios Territoriales of the Department of Environment which belongs to the Junta de Castilla y León. Ph.D. thesis where this study is included has been supported by the Junta de Castilla y León by means of a predoctoral scholarship. T. Langen (University of Clarkson, New York, NY, USA) and J. Talegón are acknowledged for their useful comments. Two anonymous reviewers contributed to improve this paper with their helpful and constructive remarks. We would also like to thank Mr. G.H. Jenkins for his help with the English version of the manuscript.

\section{References}

Akaike H (1973) Information theory as an extension of the maximum likelihood principle. In: Petrov BN, Csaki F (eds) Second international symposium on information theory. Akademiai Kiado, Budapest, pp 267-281

Barrientos LM (2000) Tamaño y composición de diferentes grupos de lobos en Castilla y León. Galemys 12:249-256

Bashore TL, Tzilkowski WM, Bellis ED (1985) Analysis of deer-vehicle collision sites in Pennsylvania. J Wildl Manage 49:769-774

Bissonette JA, Adair WA (2008) Restoring habitat permeability to roaded landscapes with isometrically-scaled wildlife crossings. Biol Conserv 141:482-488

Bissonette JA, Rosa S (2009) Road zone effects in small mammal communities. Ecol Society 14(1):27. Available in: http//www. ecologyandsociety.org/vol12/iss1/art27/

Blanco JC, Cortés Y (1999) Estudio aplicado para la gestión del lobo en hábitats fragmentados por autovías. Junta de Castilla y León, Valladolid, Informe inédito

Blanco JC, Cortés Y (2002) Ecología, censos, percepción y evolución del lobo en España: análisis de un conflicto. Sociedad Española para la Conservación y Estudio de los Mamíferos, Málaga, Spain

Blanco JC, Cortés Y, Virgós E (2005) Wolf response to two kinds of barriers in an agricultural habitat in Spain. Can J Zool 83:312323

Blanco JC, Sáenz de Buruaga M, Llaneza L (2007) Lobo Canis lupus Linnaeus, 1758. In: Palomo JL, Gisbert J, Blanco JC (eds) Atlas y Libro Rojo de los Mamíferos Terrestres de España. Dirección General para la Biodiversidad. SECEM-SECEMU, Madrid, pp $272-276$

Boitani L (2003) Wolf conservation and recovery. In: Mech LD, Boitani L (eds) Wolves: behaviour, ecology and conservation. University of Chicago Press, Chicago, pp 317-340

Burnham KP, Anderson DR (2002) Model selection and multimodal inference: a practical information-theoretic approach. Springer Verlag, New York

Clevenger AP, Waltho N (2000) Factors influencing the effectiveness of wildlife underpasses in Banff National Park, Alberta, Canada. Conserv Biol 14:47-56

Clevenger AP, Chruszcz B, Gunson KE (2001) Highway mitigation fencing reduces wildlife-vehicle collisions. Wildl Soc Bull 29:646-653

Clevenger AP, Chruszczc B, Gunson KE (2003) Spatial patterns and factors influencing small vertebrate fauna road-kill aggregations. Biol Conserv 109:15-26

Conover MR, Pitt WC, Kessler KK, DuBow TJ, Sanborn WA (1995) Review of human injuries, illness, and economic losses caused by wildlife in the United States. Wildl Soc Bull 23:407-414

Cramer JS (1999) Predictive power of the binary logit model in unbalanced samples. Statistician 48:85-94
Crooks KR (2002) Relative sensitivities of mammalian carnivores to habitat fragmentation. Conserv Biol 16:488-502

Ferreras P, Aldama JJ, Beltran JF, Delibes M (1992) Rates and causes of mortality in a fragmented population of Iberian lynx Felis pardini Temminck, 1824. Biol Conserv 61:197-202

Fielding AH, Bell JF (1997) A review of methods for the assessment of prediction errors in conservation presence/absence models. Environ Conserv 24:38-49

Finder RA, Roseberry JL, Woolf A (1999) Site and landscape conditions at white-tailed deer/vehicle collision locations in Illinois. Landscape Urban Plan 44:77-85

Foster ML, Humphrey SR (1995) The use of highway underpasses by Florida panthers and other wildlife. Wildl Soc Bull 23:95-100

Fuller TK (1989) Population dinamycs of wolves in north-central Minnesota. Wildl Monogr 105:1-41

Gloyne CC, Clevenger AP (2001) Cougar Puma concolor use of wildlife crossing structures on the Trans-Canada Highway in Banff National Park, Alberta. Wildl Biol 7:117-124

Grilo C, Bissonette JA, Santos-Reis M (2008) Response of carnivores to existing highway culverts and underpasses: implications for road planning and mitigation. Biodivers Conserv 17:1685-1699

Grilo C, Bissonette JA, Santos-Reis M (2009) Spatial-temporal patterns in Mediterranean carnivore road casualties: consequences for mitigation. Biol Conserv 142:301-313

Groot-Bruinderink GWTA, Hazebroek E (1996) Ungulate traffic collisions in Europe. Conserv Biol 10:1059-1067

Gunson KE, Clevenger AP, Ford AT, Bissonette JA, Hardy A (2009) A comparison of data sets varying in spatial accuracy used to predict the occurrence of wildlife-vehicle collisions. Environ Manag 44:268-277

Guzmán JN, García FJ, Garrote G, Pérez de Ayala R, Iglesias C (2004) El lince ibérico (Lynx pardinus) en España y Portugal. Censo-diagnóstico de sus poblaciones, Dirección General para la Biodiversidad, Madrid

Harris LD, Gallagher PB (1989) New initiatives for wildlife conservation: the need for movement corridors. In: Mackintosh $\mathrm{G}$ (ed) Defense of wildlife: preserving corridors and communities. Defenders of Wildlife, Washington, pp 11-34

Hubbard MW, Danielson BJ, Schmitz RA (2000) Factors influencing the location of deer-vehicle accidents in Iowa. J Wildl Manage 64:707-713

Huber D, Kusak J, Frkovic A, Guzvica G, Gomercic T (2002) Causes of wolf mortality in Croatia in the period 1986-2001. Vet Arh 72:131-139

Imai K, King G, Lau O (2007) Zelig: Everyone's Statistical Software. Available in: http://GKing.harvard.edu/zelig

Imai K, King G, Lau O (2008) Toward a common framework for statistical analysis and development. J Comput Graph Stat 17:892-913. Available in: http://gking.harvard.edu/files/abs/zabs.shtml

Inbar M, Mayer RT (1999) Spatio-temporal trends in armadillo diurnal activity and road-kills in central Florida. Wildl Soc Bull 27:865872

Iuell B, Bekker H, Cuperus R, Dufek J, Fry GL, Hicks C, Hlavac V, Keller J, Le Marie Wandall B, Rosell Pagès C, Sangwine T, Torslov N (eds) (2003) Wildlife and traffic: a European handbook for identifying conflicts and designing solutions. Prepared by COST 341: Habitat fragmentation due to transportation infrastructure. Ministry of Transport, Public Works and Water Management, Road and Hydraulic Engineering Division, Delft, the Netherlands

Jaeger JAG, Fahrig L (2004) Effects of road fencing on population persistence. Conserv Biol 18:1651-1657

Joyce TL, Mahoney SP (2001) Spatial and temporal distributions of moose-vehicle collisions in Newfoundland. Wildl Soc Bull 29:281-291 
Kaczensky P, Knauer F, Krze B, Jonozovic M, Adamic M, Gossow H (2003) The impact of high speed, high volume traffic axes on brown bears in Slovenia. Biol Conserv 111:191-204

King G, Zeng L (2000) Explaining rare events in international relations. Int Organ 55:693-715

King G, Zeng L (2001) Logistic regression in rare events data. Polit Anal 9:137-163

Kohn B, Frair J, Unger D, Gehring T, Shelley D, Anderson E, Keenlance P (1999) Impacts of a highway expansion project on wolves in northwestern Wisconsin. In: Evink G, Zeigler D, Garrett P (eds) Proceedings of the Third International Conference on Wildlife Ecology and Transportation. Florida Department of Transportation, Tallahassee, pp 53-65

Kolowski JM, Nielsen CK (2008) Using penrose distance to identify potential risk of wildlife-vehicle collisions. Biol Conserv 141:1119-1128

Lavsund S, Sandegren F (1991) Moose-vehicle relations in Sweden: a review. Alces 27:118-126

Llaneza L, Blanco JC (2005) Situación del lobo (Canis lupus L.) en Castilla y León en 2001. Evolución de sus poblaciones. Galemys 17:2015-2028

Lovari S, Sforzi A, Scala C, Fico R (2007) Mortality parameters of the wolf in Italy: does the wolf keep himself from the door? J Zool 272:117-124

Mace RD, Waller JS, Manley TL, Lyon JL, Zuuring H (1996) Relationships among grizzly bears, roads, and habitat in the Swan Mountains, Montana. J Appl Ecol 33:1395-1404

Maehr DS, Land ED, Roelke ME (1991) Mortality patterns of panthers in Southwest Florida. Proc Annu Conf Southeast Assoc Fish Wildl Agencies 45:201-217

Malo JE, Suarez F, Diez A (2004) Can we mitigate animal-vehicle accidents using predictive models? J Appl Ecol 41:701-710

McLellan BN, Shackleton DM (1988) Grizzly bears and resource extraction industries: effects of roads on behaviour, habitat use and demography. J Appl Ecol 25:451-460

Mech LD (1989) Wolf population survival in an area of high road density. Am Midl Nat 121:387-389

Mech LD (1995) The challenge and opportunity of recovering wolf populations. Conserv Biol 9:270-278

Ministerio de Medio Ambiente (2004) Incidencias y mortalidad de Lince Ibérico encontradas en el Área de Doñana. Available in: http://www. catsg.org/iberianlynx/04_library/4_6_materialandmethods/Grupo Asesor_de_Aspectos_Sanitarios_2004_Tabla_Mortalidad_ Linces $1982-2004$.pdf

Mladenoff DJ, Sickley TA, Haight RG, Wydeven AP (1995) A regional landscape analysis and prediction of favorable gray wolf habitat in the Northern Great Lakes Region. Conserv Biol 9:279294

Mysterud A (2004) Temporal variation in the number of car-killed red deer Cervus elaphus in Norway. Wildlife Biol 10:203-211

Nielsen CK, Anderson RG, Grund MD (2003) Landscape influences on deer-vehicle accident areas in an urban environment. J Wildl Manage 67:46-51
Noss RF, Quigley HB, Hornocker MG, Merrill T, Paquet PC (1996) Conservation biology and carnivore conservation in the Rocky Mountains. Conserv Biol 10:949-963

Olsen ML (2003) Causes of mortality of free-ranging Scandinavian grey wolves, 1977-2003. Project paper, Norwegian School of Veterinary Science, Tromsø

Paquet P, Callaghan C (1996) Effect of linear developments on winter movements of gray wolves in the Bow River Valley of Banff National Park, Alberta. In: transportation and wildlife: reducing wildlife mortality and improving wildlife passageways across transportation corridors. Proceedings of Florida Department of Transportation/FHWA Transportation related, Florida

Pearce J, Ferrier S (2000) Evaluating the predictive performance of habitat models developed using logistic regression. Ecol Model 133:225-245

Pletscher DH, Ream RR, Boyd DK, Fairchild MW, Kunkel KE (1997) Populations dynamics of a recolonizing wolf population. J Wildl Manage 61:459-465

Puglisi MJ, Lindzey JS, Bellis ED (1974) Factors associated with highway mortality of white-tailed deer. J Wildl Manage 38:799 807

Ramp D, Caldwell J, Edwards KA, Warton D, Croft DB (2005) Modelling of wildlife fatality hotspots along the Snowy Mountain Highway in New South Wales, Australia. Biol Conserv 126:474-490

Rodriguez A, Crema G, Delibes M (1996) Use of nonwildlife passages across a high speed railway by terrestrial vertebrates. J Appl Ecol 33:1527-1540

Rodríguez A, Crema G, Delibes M (1997) Factors affecting crossing of red foxes and wild cats through non-wildlife passages across a high-speed railway. Ecography 20:287-294

Seiler A (2004) Trends and spatial pattern in ungulate-vehicle collisions in Sweden. Wildlife Biol 10:301-313

Seiler A (2005) Predicting locations of moose-vehicle collisions in Sweden. J Appl Ecol 42:371-382

Slater FM (2002) An assessment of wildlife road casualties - the potential discrepancy between numbers counted and numbers killed. Web Ecol 3:33-42

Thiel RP (1985) Relationship between road densities and wolf habitat suitability in Wisconsin. Am Midl Nat 113:404-407

Thurber JM, Peterson RO, Drummer TD, Thomasma SA (1994) Gray wolf response to refuge boundaries and roads in Alaska. Wildl Soc Bull 22:61-68

Tigas LA, Van Vuren DH, Sauvajot RM (2002) Behavioral responses of bobcats and coyotes to habitat fragmentation and corridors in an urban environment. Biol Conserv 108:299-306

Todd AW, Keith LB (1976) Responses of coyotes to winter reductions in agricultural carrion. Alberta Wildl Tech Bull 5:32

Ward AL (1982) Mule deer behavior in relation to fencing and underpasses on Interstate 80 in Wyoming. Transp Res Rec 859:8-13

Waser PM (1996) Patterns and consequences of dispersal in gregarious carnivores. In: Gittleman JL (ed) Carnivore behavior, ecology, and evolution. Cornell University Press, Ithaca, pp 267 295 